\title{
MicroRNAs as prognostic molecular signatures in renal cell carcinoma: a systematic review and meta-analysis
}

\author{
Liangyou Gu${ }^{1, *}$, Hongzhao $\mathrm{Li}^{1, *}$, Luyao Chen ${ }^{1, *}$, Xin Ma ${ }^{1}$, Yu Gao ${ }^{1}$, Xintao $\mathrm{Li}^{1}$, \\ Yu Zhang ${ }^{1}$, Yang Fan ${ }^{1}$, Xu Zhang ${ }^{1}$ \\ ${ }^{1}$ Department of Urology/State Key Laboratory of Kidney Diseases, Chinese PLA General Hospital/PLA Medical School, Beijing \\ 100853, P.R. China \\ *These authors have contributed equally to this work \\ Correspondence to: \\ Xu Zhang, e-mail: xzhang@foxmail.com \\ Keywords: microRNA, renal cell carcinoma, survival, prognosis biomarker, meta-analysis \\ Received: April 27, $2015 \quad$ Accepted: September 11, $2015 \quad$ Published: September 22, 2015
}

\section{ABSTRACT}

This is a systematic review of studies investigating the prognostic value of different microRNAs (miRs) in renal cell carcinoma (RCC). Twenty-seven relevant studies were identified, with a total of 2578 subjects. We found that elevated expression of miR-21, miR-1260b, miR-210, miR-100, miR-125b, miR-221, miR630 , and miR-497 was associated with a poor prognosis in RCC patients. Conversely, decreased expression of miR-106b, miR-99a, miR-1826, miR-215, miR-217, miR-187, miR-129-3p, miR-23b, miR-27b, and miR-126 was associated with a worse prognosis. We performed meta-analyses on studies to address the prognostic value of $\mathbf{m i R - 2 1}$, miR-126, miR-210, and miR-221. This revealed that elevated miR-21 expression was associated with shorter overall survival (OS; hazard ratio [HR], 2.29; 95\% confidence interval $[\mathrm{CI}], 1.28-4.08$ ), cancer specific survival (CSS; HR, 4.16; 95\% CI, 2.496.95), and disease free survival (DFS; HR, 2.15; 95\% CI, 1.16-3.98). The decreased expression of miR-126 was associated with shorter CSS (HR, 0.35; 95\% CI, 0.150.85 ), OS (HR, 0.45; 95\% CI, 0.30-0.69), and DFS (HR 0.30; 95\% CI, 0.18-0.50). Our comprehensive systematic review reveals that miRs, especially miR-21 and miR-126, could be promising prognostic markers and useful therapeutic targets in RCC.

\section{INTRODUCTION}

A total of 63,920 new kidney and renal pelvis cancers were estimated to occur in the United States in 2014, and 13,860 deaths were related to these malignancies [1]. Epidemiologic data have shown a rapid rise in the incidence of renal cell carcinoma (RCC) [2]. RCC is the most common form of kidney cancer in adults, and is comprised of four major histologic subtypes, clear cell RCC (ccRCC), papillary $\mathrm{RCC}$, chromophobe RCC, and oncocytomas. ccRCC remains the most aggressive and common subtype of RCC, accounting for $75 \%$ to $80 \%$ of cases [3]. Approximately $20-30 \%$ of RCC patients have metastatic disease at the time of diagnosis, and another 30\% who undergo curative surgery for localized RCC develop metastasis during follow-up [4]. Hence, a means of identifying patients with a poor prognosis, and who may benefit from aggressive treatment, is greatly needed.
The currently used system to predict prognosis is based on clinicopathological parameters [5], but does not accurately stratify patients, or predict the natural outcome of the disease, especially in localized RCC [6]. Therefore, molecular biomarkers that can improve the accuracy of predictions when used alone or in combination with other clinical parameters are urgently needed to better guide clinical decisions.

Although there has been widespread research into genetic biomarkers for RCC, epigenetic biomarkers including microRNAs (miRs) have also received considerable attention because of their biological and clinical utility in diagnosis and treatment [7]. MiRs are a class of small ( $\sim 22$ nucleotide) noncoding RNAs that regulate post-transcriptional gene expression epigenetically, through RNA interference. This is usually mediated by their direct interaction with the $3^{\prime}$-UTR of complementary mRNA target transcripts, which facilitates 
their degradation or inhibits their translation [8]. After their initial identification in 1993 by Lee et al [9], the study of miRs has revealed new mechanisms for the regulation of gene expression and provided new directions in cancer research. MiRs are involved in a variety of biological functions, including cellular proliferation and cell cycle control, apoptosis, angiogenesis, tissue invasion, and metastasis, suggesting that they have a vital role in the development and progression of different cancers [10-12]. Correspondingly, miRs have also been shown to have prognostic significance in several tumor types, including colon [13], lung [14], breast [15], and ovarian cancer [16]. Recent studies have shown that miRs are also potential prognostic factors in RCC, suggesting that they could be developed as prognostic biomarkers to guide therapeutic decisions [17-19].

To date there has only been one published study evaluating the prognostic value of different miRs in RCC [7], and this did not follow the MOOSE or PRISMA guidelines, and had only a limited analysis of prognosis. Therefore, we conducted a systematic review of studies that have identified a relationship between miR expression and survival in RCC, and included these in a metaanalyses if the extracted data could be merged.

\section{RESULTS}

\section{Selection of studies}

A total of 597 records were retrieved from the primary literature of the below databases. A total of 125 duplicate reports were excluded. After screening the titles of 597 studies returned from the initial search strategy, the abstracts of 106 of these studies were reviewed. This left 44 articles that met the inclusion criteria. After screening the titles, abstracts, publication types, and full texts of these articles, 27 studies were included in the present study and used for data extraction (Figure 1 and Table 1). We then examined whether a sufficient number of these 27 studies pertained to specific miRs to allow a meta-analysis to be conducted. Finally, a total of 12 publications addressing the relationship between four specific miRs (miR-21, miR126, miR-210, and miR-221) and RCC were found to meet all of the inclusion criteria. These also provided the total data set for the meta-analysis [20-31]. All of the selected studies were nonrandomized. A flowchart of the study selection process is shown in Figure 1.

\section{Characteristics of the included studies}

All of the included studies were published recently (2010-2015). They had a retrospective design, and reported the prognostic value of 21 different miRs in RCC patients, with a median sample size of 86 patients (range, 31-276 patients). Quantitative real-time PCR was used by most of the studies to measure miR expression, whereas in situ hybridization and microarray was used by only one study. MiR expression was mainly detected in tissue samples, while one study tested for miRs in plasma. In 12 studies, the hazard ratio (HR) was adjusted for other associated variables (covariates) including tumor site and size, patient age, tumor grade, and patient stage (Table 1).

\section{MiRs and prognosis}

Increased expression of miR-21 [21, 22, 26, 27, 31], miR-1260b [32], miR-210 [28, 30, 31], miR-100 [33], miR$125 \mathrm{~b}$ [34], miR-221 [25, 27], miR-630 [35], and miR-497 [36] were associated with a poor prognosis, as was the decreased expression of miR-106b [37], miR-99a [38], miR1826 [39], miR-215 [40], miR-217 [41], miR-187 [42], miR129-3p [43], miR-23b [44], miR-27b [44], and miR-126 [26, 27, 29] (Table 2 and Figure 2). MiR-222 expression did not show any significant association with cancer survival [25]. Although the expression of miR-486 [45] and miR-155 [46] was associated with the survival outcome of patients with stage III or IV RCC, it was not significantly associated with the prognosis of patients with all-stage RCC.

Four miRs (miR-21, miR-126, miR-210 and miR221) were investigated by at least two studies, and we conducted meta-analyses of the corresponding data. Five articles included survival data for miR-21, two articles contained OS data $[21,22]$, three had CSS data $[26,27$, $31]$, and one had DFS data [21]. When we performed a meta-analysis on the relationship of miR-21 expression and the OS and CSS of RCC patients, no significant heterogeneity was found $\operatorname{COS}, I^{2}=14.2 \%, P=0.280$; CSS, $\left.I^{2}=0.0 \%, P=0.585\right)$, and the fixed-effect model was therefore applied. This revealed that a higher miR-21 expression was predictive of shorter OS (HR, 2.29; 95\% confidence interval [CI], 1.28-4.08; $P=0.005)$ and CSS (HR, 4.16; 95\% CI, 2.49-6.95; $P<0.001$ ). Faragalla et al. [21] also reported a shorter DFS in RCC patients with an elevated level of miR-21 (HR, 2.15; 95\% CI, 1.16-3.98; $P=0.014$ ) (Figure 3A). Three articles addressed the role of miR-126 in the survival outcome of RCC patients, two of which focused on CSS [26, 27], and one focused on OS and DFS [29]. There was significant heterogeneity among the selected studies with respect to CSS $\left(I^{2}=55.5 \%, P\right.$ $=0.134)$, and thus a random-effect model was used. The results showed that lower miR-126 expression predicted a shorter CSS (HR, 0.35; 95\% CI, 0.15-0.85; $P=0.019)$. Unlike CSS, there was no significant heterogeneity in OS $\left(I^{2}=0.0 \%, P=0.694\right)$, and hence a fixed-effect model was applied. This indicated that lower miR-126 expression was associated with shorter OS in RCC (HR, 0.45; 95\% CI, 0.30-0.69; $P<0.001)$. In addition, Khella et al. [29] reported shorter DFS (HR, 0.30; 95\% CI, 0.18-0.50; $P<$ $0.001)$ in RCC patients with reduced miR-126 expression (Figure 3B). 


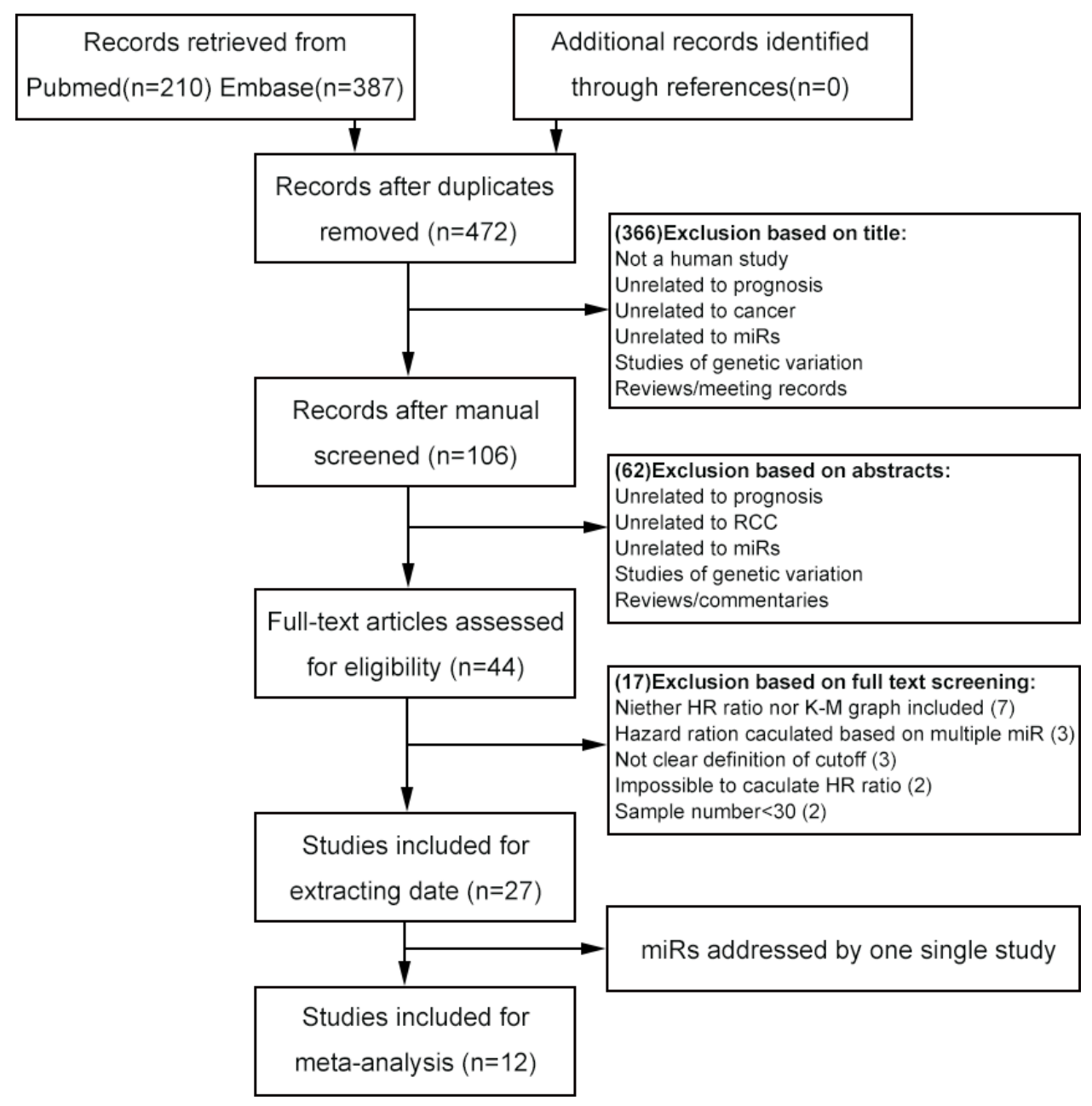

Figure 1: Flowchart of selecting studies for inclusion.

Seven articles addressed the relationship between miR-210 expression and the prognosis of RCC patients, of which four included OS data $[20,23,28,30]$, one included data on DFS [30], and two included data on CSS $[27,31]$ and RFS $[24,28]$. Because of significant interstudy heterogeneity, a random-effect model was applied in the analysis $\left(I^{2}=86.0 \%, P=0.000\right)$. This revealed that increased miR-210 expression tended to occur in patients with a shorter OS, although this was not statistically significant (HR, 1.78; 95\% CI, 0.49-6.55; $P=0.162$ ). Additionally, Samaan et al. [30] found that there was a shorter DFS in patients with elevated miR-210 levels (HR, $1.82 ; 95 \%$ CI, 1.11-2.99; $P=0.018$ ). However, miR-210 expression was not found to be related to CSS (HR, 1.64; $95 \% \mathrm{CI}, 0.61-4.37 ; P=0.138)$ or RFS (HR, $2.79 ; 95 \% \mathrm{CI}$, $0.05-169.62 ; P=0.810$ ) (Figure 4A).

For miR-221, one study included OS and CSS data [25], and one contained only CSS data [27]. A randomeffect model was used due to significant inter-study heterogeneity $\left(I^{2}=83.9 \%, P=0.013\right)$, and revealed that aberrant miR-221 expression was not related to CSS
(HR, 2.26; 95\% CI, 0.16-31.39; $P=0.543$ ). In addition, Teixeira et al. [25] reported that an increased plasma level of miR-221 was associated with shorter OS (HR, 4.20; 95\% CI, 1.21-14.58; $P=0.024$ ) (Figure 4B).

Due to the small size of this study, no conclusive graph could be generated, and we therefore did not evaluate publication bias.

\section{DISCUSSION}

Over the past decade, there has been increasing evidence that aberrant expression of several miRs is associated with survival outcome in cancer patients [47-50]. MiRs are also known to play key roles in the pathogenesis of cancer, as the up-regulation of oncogenic miRs or the down-regulation of cancer suppressive miRs can contribute to tumorigenesis through effects on many cellular process, including the cell cycle, angiogenesis, invasion, and metastasis [51, 52].

In response to the need for independent prognostic molecular markers for RCC that are readily 
Table 1: The main characteristics of enrolled studies

\begin{tabular}{|c|c|c|c|c|c|c|c|c|c|c|c|c|}
\hline $\begin{array}{l}\text { Study } \\
\text { (year) }\end{array}$ & $\mathrm{miR}$ & $\begin{array}{l}\text { Popu- } \\
\text { lation }\end{array}$ & $\begin{array}{l}\text { Study } \\
\text { design }\end{array}$ & Stage & $\begin{array}{c}\text { Case } \\
\text { number }\end{array}$ & $\begin{array}{l}\text { Assay } \\
\text { method }\end{array}$ & Cut-off & $\begin{array}{l}\text { Detected } \\
\text { sample }\end{array}$ & $\begin{array}{c}\text { Survival } \\
\text { analysis }\end{array}$ & $\begin{array}{c}\text { Source } \\
\text { of } \mathrm{HR}\end{array}$ & $\begin{array}{l}\text { Adju- } \\
\text { sted }\end{array}$ & $\begin{array}{c}\text { Follow } \\
\text { up(month) }\end{array}$ \\
\hline Neal 2010 & 210 & Australia & $\mathrm{R}$ & $\begin{array}{l}\text { pT1- } \\
\text { pT4 }\end{array}$ & 31 & qRT-PCR & $\begin{array}{l}\text { Maximum } \\
\text { NT value }\end{array}$ & Tissue & OS & $\mathrm{DE} / \mathrm{SC}$ & - & $\sim 140$ \\
\hline $\begin{array}{l}\text { Slaby } \\
2010\end{array}$ & $106 \mathrm{~b}$ & Czech & $\mathrm{R}$ & $\begin{array}{l}\text { T1- } \\
\text { T3 }\end{array}$ & 38 & qRT-PCR & Median & $\begin{array}{c}\text { Frozen } \\
\text { tissue }\end{array}$ & RFS & $\mathrm{SC}$ & - & $3 \sim 105$ \\
\hline Cui 2012 & $99 a$ & China & $\mathrm{R}$ & $\begin{array}{l}\text { T1- } \\
\text { T4 }\end{array}$ & 40 & qRT-PCR & $\begin{array}{l}\mathrm{T} / \mathrm{N} \text { ratio } \\
<0.5\end{array}$ & $\begin{array}{c}\text { Frozen } \\
\text { tissue }\end{array}$ & OS & $\mathrm{SC}$ & - & $\sim 70$ \\
\hline $\begin{array}{l}\text { Faragalla } \\
2012\end{array}$ & 21 & Canada & $\mathrm{R}$ & $\begin{array}{l}\text { T1- } \\
\text { T3 }\end{array}$ & 88 & qRT-PCR & $\begin{array}{c}\text { 40th } \\
\text { percentile }\end{array}$ & Tissue & OS, DFS & Rep & Yes & $\sim 192$ \\
\hline $\begin{array}{l}\text { Hirata } \\
2012\end{array}$ & 1826 & Japan & $\mathrm{R}$ & $\begin{array}{l}\text { T1- } \\
\text { T4 }\end{array}$ & 46 & qRT-PCR & Median & Tissue & OS, RFS & $\mathrm{SC}$ & - & $\sim 120$ \\
\hline $\begin{array}{l}\text { Zaman } \\
2012\end{array}$ & 21 & USA & $\mathrm{R}$ & - & 36 & qRT-PCR & $\begin{array}{c}\mathrm{T} / \mathrm{N} \text { ratio } \\
>1.2\end{array}$ & FFPE & OS & $\mathrm{SC}$ & - & $\sim 60$ \\
\hline \multirow[t]{2}{*}{$\begin{array}{l}\text { Goto } \\
2013\end{array}$} & 486 & Japan & $\mathrm{R}$ & I-IV & 150 & qRT-PCR & Quartile & FFPE & CSS & $\mathrm{SC}$ & - & $2-120$ \\
\hline & 486 & Japan & $\mathrm{R}$ & III-IV & 46 & qRT-PCR & Quartile & FFPE & CSS & Rep & Yes & $2-120$ \\
\hline $\begin{array}{l}\text { Hirata } \\
2013\end{array}$ & $1260 \mathrm{~b}$ & Japan & $\mathrm{R}$ & $\begin{array}{l}\text { pT1- } \\
\text { pT4 }\end{array}$ & 43 & qRT-PCR & Median & FFPE & OS & $\mathrm{SC}$ & - & $\sim 110$ \\
\hline $\begin{array}{l}\text { Khella } \\
2013\end{array}$ & 215 & Canada & $\mathrm{R}$ & - & 218 & qRT-PCR & $\begin{array}{c}\text { X-tile } \\
\text { algorithm }\end{array}$ & Tissue & OS & $\mathrm{SC}$ & - & $\sim 100$ \\
\hline Li 2013 & 217 & China & $\mathrm{R}$ & $\begin{array}{l}\text { T1- } \\
\text { T4 }\end{array}$ & 44 & qRT-PCR & $\begin{array}{c}\mathrm{T} / \mathrm{N} \text { ratio } \\
<0.49\end{array}$ & $\begin{array}{c}\text { Frozen } \\
\text { tissue }\end{array}$ & OS & $\mathrm{DE} / \mathrm{SC}$ & - & $\sim 60$ \\
\hline $\begin{array}{l}\text { McCor- } \\
\text { mick } 2013\end{array}$ & 210 & UK & $\mathrm{R}$ & $\begin{array}{l}\text { T1- } \\
\text { T3 }\end{array}$ & 46 & qRT-PCR & Median & Tissue & OS & Rep & - & $\sim 100$ \\
\hline \multirow[t]{2}{*}{$\begin{array}{l}\text { Shinmei } \\
2013\end{array}$} & 155 & Japan & $\mathrm{R}$ & I-IV & 137 & qRT-PCR & Median & FFPE & CSS & $\mathrm{SC}$ & - & $2 \sim 188$ \\
\hline & 155 & Japan & $\mathrm{R}$ & III-IV & 43 & qRT-PCR & Median & FFPE & CSS & $\mathrm{SC}$ & - & $2 \sim 188$ \\
\hline $\begin{array}{l}\text { Wang } \\
2013\end{array}$ & 100 & China & $\mathrm{R}$ & $\begin{array}{l}\text { T1- } \\
\text { T4 }\end{array}$ & 96 & qRT-PCR & Median & $\begin{array}{c}\text { Frozen } \\
\text { tissue }\end{array}$ & OS, CSS & Rep & Yes & $25 \sim 134$ \\
\hline $\begin{array}{l}\text { Wotschof- } \\
\text { sky } 2013\end{array}$ & 210 & Germany & $\mathrm{R}$ & $\begin{array}{l}\text { pT1- } \\
\text { pT4 }\end{array}$ & 87 & qRT-PCR & Median & $\begin{array}{c}\text { Frozen } \\
\text { tissue }\end{array}$ & RFS & Rep & - & $\sim 80$ \\
\hline $\begin{array}{l}\text { Zhao } \\
2013\end{array}$ & 187 & China & $\mathrm{R}$ & $\begin{array}{l}\text { T1- } \\
\text { T4 }\end{array}$ & 86 & qRT-PCR & $\begin{array}{c}\mathrm{T} / \mathrm{N} \text { ratio } \\
<0.42\end{array}$ & $\begin{array}{c}\text { Frozen } \\
\text { tissue }\end{array}$ & OS & $\mathrm{DE} / \mathrm{SC}$ & - & $\sim 60$ \\
\hline $\begin{array}{l}\text { Chen } \\
2014\end{array}$ & $\begin{array}{c}129- \\
3 p\end{array}$ & China & $\mathrm{R}$ & $\begin{array}{l}\text { pT1- } \\
\text { pT4 }\end{array}$ & 69 & qRT-PCR & Median & Tissue & OS, DFS & Rep & - & $\sim 44$ \\
\hline Fu 2014 & $125 b$ & China & $\mathrm{R}$ & I-IV & 276 & ISH & $\begin{array}{c}\text { X-tile } \\
\text { program }\end{array}$ & FFPE & $\begin{array}{l}\text { CSS, } \\
\text { RFS }\end{array}$ & Rep & Yes & $\sim 120$ \\
\hline \multirow[t]{2}{*}{$\begin{array}{l}\text { Ishihara } \\
2014\end{array}$} & $23 b$ & Japan & $\mathrm{R}$ & $\begin{array}{l}\text { pT1- } \\
\text { pT4 }\end{array}$ & 61 & qRT-PCR & Median & Tissue & OS & $\mathrm{SC}$ & - & $\sim 108$ \\
\hline & $27 b$ & Japan & $\mathrm{R}$ & $\begin{array}{l}\text { pT1- } \\
\text { pT4 }\end{array}$ & 61 & qRT-PCR & Median & Tissue & OS & $\mathrm{SC}$ & - & $\sim 108$ \\
\hline \multirow[t]{2}{*}{$\begin{array}{l}\text { Teixeira } \\
2014\end{array}$} & 221 & Portugal & $\mathrm{R}$ & $\begin{array}{l}\text { T1- } \\
\text { T3 }\end{array}$ & 43 & qRT-PCR & Quartile & Plasma & OS, CSS & $\begin{array}{l}\mathrm{SC} / \\
\mathrm{Rep}\end{array}$ & $-/$ Yes & $\sim 130$ \\
\hline & 222 & Portugal & $\mathrm{R}$ & $\begin{array}{l}\text { T1- } \\
\text { T3 }\end{array}$ & 43 & qRT-PCR & Quartile & Plasma & OS & $\mathrm{SC}$ & - & $\sim 130$ \\
\hline
\end{tabular}

(Continued) 


\begin{tabular}{|c|c|c|c|c|c|c|c|c|c|c|c|c|}
\hline $\begin{array}{l}\text { Study } \\
\text { (year) }\end{array}$ & miR & $\begin{array}{l}\text { Popu- } \\
\text { lation }\end{array}$ & $\begin{array}{l}\text { Study } \\
\text { design }\end{array}$ & Stage & $\begin{array}{c}\text { Case } \\
\text { number }\end{array}$ & $\begin{array}{l}\text { Assay } \\
\text { method }\end{array}$ & Cut-off & $\begin{array}{c}\text { Detected } \\
\text { sample }\end{array}$ & $\begin{array}{c}\text { Survival } \\
\text { analysis }\end{array}$ & $\begin{array}{c}\text { Source } \\
\text { of HR }\end{array}$ & $\begin{array}{l}\text { Adju- } \\
\text { sted }\end{array}$ & $\begin{array}{c}\text { Follow } \\
\text { up(month) }\end{array}$ \\
\hline \multirow[t]{2}{*}{$\begin{array}{l}\text { Vergho } \\
2014\end{array}$} & 21 & Germany & $\mathrm{R}$ & $\begin{array}{l}\text { pT1- } \\
\text { pT3 }\end{array}$ & 103 & qRT-PCR & $\begin{array}{l}\text { ROC } \\
\text { curve }\end{array}$ & $\begin{array}{c}\text { Frozen } \\
\text { tissue }\end{array}$ & CSS & Rep & Yes & $\sim 68$ \\
\hline & 126 & Germany & $\mathrm{R}$ & $\begin{array}{l}\text { pT1- } \\
\text { pT3 }\end{array}$ & 103 & qRT-PCR & $\begin{array}{l}\text { ROC } \\
\text { curve }\end{array}$ & $\begin{array}{l}\text { Frozen } \\
\text { tissue }\end{array}$ & CSS & $\mathrm{SC}$ & - & $\sim 68$ \\
\hline \multirow[t]{4}{*}{$\begin{array}{l}\text { Vergho } \\
2014\end{array}$} & 21 & Germany & $\mathrm{R}$ & $\mathrm{T} 3$ & 37 & qRT-PCR & $\begin{array}{l}\text { ROC } \\
\text { curve }\end{array}$ & FFPE & CSS & Rep & - & $\sim 152$ \\
\hline & 126 & Germany & $\mathrm{R}$ & $\mathrm{T} 3$ & 37 & qRT-PCR & $\begin{array}{l}\text { ROC } \\
\text { curve }\end{array}$ & FFPE & CSS & Rep & - & $\sim 152$ \\
\hline & 210 & Germany & $\mathrm{R}$ & $\mathrm{T} 3$ & 37 & qRT-PCR & $\begin{array}{l}\text { ROC } \\
\text { curve }\end{array}$ & FFPE & CSS & Rep & - & $\sim 152$ \\
\hline & 221 & Germany & $\mathrm{R}$ & $\mathrm{T} 3$ & 37 & qRT-PCR & $\begin{array}{l}\text { ROC } \\
\text { curve }\end{array}$ & FFPE & CSS & Rep & - & $\sim 152$ \\
\hline $\begin{array}{l}\text { Zhao } \\
2014\end{array}$ & 630 & China & $\mathrm{R}$ & $\begin{array}{l}\mathrm{T} 1- \\
\mathrm{T} 4\end{array}$ & 92 & qRT-PCR & Mean & $\begin{array}{c}\text { Frozen } \\
\text { tissue }\end{array}$ & OS & Rep & Yes & - \\
\hline Ge 2015 & 210 & USA & $\mathrm{R}$ & I-IV & 58 & Microarray & Median & Tissue & OS, RFS & $\begin{array}{l}\mathrm{SC} / \\
\mathrm{Rep}\end{array}$ & $-/$ Yes & $31.5 \sim 86.1$ \\
\hline \multirow[t]{2}{*}{$\begin{array}{l}\text { Khella } \\
2015\end{array}$} & 126 & Canada & $\mathrm{R}$ & I-IV & 260 & qRT-PCR & $\begin{array}{c}\text { X-tile } \\
\text { algorithm }\end{array}$ & Tissue & OS, DFS & Rep & Yes & $\sim 120$ \\
\hline & 126 & USA & $\mathrm{R}$ & T1b- & 268 & qRT-PCR & $\begin{array}{c}\text { X-tile } \\
\text { algorithm }\end{array}$ & Tissue & OS & Rep & - & $\sim 120$ \\
\hline $\begin{array}{l}\text { Samaan } \\
2015\end{array}$ & 210 & Canada & $\mathrm{R}$ & I-IV & 262 & qRT-PCR & $\begin{array}{c}\text { X-tile } \\
\text { algorithm }\end{array}$ & Tissue & OS, DFS & Rep & Yes & $\sim 120$ \\
\hline \multirow[t]{2}{*}{$\begin{array}{l}\text { Tang } \\
2015\end{array}$} & 21 & China & $\mathrm{R}$ & - & 45 & qRT-PCR & $\begin{array}{c}\text { X-tile } \\
\text { algorithm }\end{array}$ & $\begin{array}{c}\text { Frozen } \\
\text { tissue }\end{array}$ & CSS & Rep & Yes & $\sim 58.4$ \\
\hline & 210 & China & $\mathrm{R}$ & - & 45 & qRT-PCR & $\begin{array}{c}\text { X-tile } \\
\text { algorithm }\end{array}$ & $\begin{array}{c}\text { Frozen } \\
\text { tissue }\end{array}$ & CSS & Rep & Yes & $\sim 58.4$ \\
\hline $\begin{array}{l}\text { Zhao } \\
2015\end{array}$ & 497 & China & $\mathrm{R}$ & $\begin{array}{l}\text { T1- } \\
\text { T4 }\end{array}$ & 86 & qRT-PCR & Mean & $\begin{array}{c}\text { Frozen } \\
\text { tissue }\end{array}$ & OS & Rep & Yes & $\sim 60$ \\
\hline
\end{tabular}

$\mathrm{HR}=$ hazard ratio; $\mathrm{MiR}=$ microRNA; $\mathrm{R}=$ Retrospective; qRT-PCR $=$ quantities reverse transcription polymerase chain reaction; ISH = in situ hybridization; FFPE = formalin-fixed, paraffin-embedded; OS = overall survival; RFS = recurrence free survival; DFS = disease free survival; CSS = cancer specific survival; $\mathrm{DE}=$ data extrapolated; $\mathrm{SC}=$ survival curve; Rep $=$ Reported; - , not reported.

assayable on routinely acquired clinical specimens, we conducted this comprehensive systematic review and meta-analysis of the current literature on RCC, evaluated the inconsistencies between these reports, and undertook a comprehensive assessment of the prognostic value of miRs. Our study is the first extensive report focusing on this association, in which 27 studies involving 2578 subjects were analyzed and 21 miRs involved in the survival analysis of RCC were compared.

In the current study, we found that the elevated expression of miR-21 [21, 22, 26, 27, 31], miR-1260b [32], miR-210 [28, 30, 31], miR-100 [33], miR-125b [34], miR-221 [25, 27], miR-630 [35], and miR-497 [36] were associated with poor survival in RCC patients, whilst the decreased expression of miR-106b [37], miR-99a [38], miR-1826 [39], miR-215 [40], miR-217 [41], miR-187
[42], miR-129-3p [43], miR-23b [44], miR-27b [44], and miR-126 [26, 27, 29] were likewise associated with a worse prognosis.

Although a number of miRs were found to be associated with the prognosis of RCC patients, most of them were identified only by a single study, and only four miRs (miR-21, miR-126, miR-210 and miR-221) were reported by at least two studies. We therefore performed the meta-analyses on these four miRs and merged the data. The results indicate that an elevated miR-21 level predicts poor survival in RCC patients, who are likely to have shorter OS, CSS, and DFS. Conversely, a lower expression level of miR-126 predicts worse CSS, OS, and DFS in RCC patients. Furthermore, increased expression of miR-210 is associated with shorter DFS, and an elevated plasma level of miR-221 is associated with shorter OS. 
Table 2: Hazard ratios for microRNAs

\begin{tabular}{|c|c|c|c|c|c|c|c|c|c|c|}
\hline \multirow[t]{2}{*}{ Study } & \multirow[t]{2}{*}{ miR } & \multicolumn{2}{|c|}{ Case number } & \multicolumn{2}{|l|}{ OS } & \multicolumn{2}{|c|}{ CSS/DFS } & \multicolumn{2}{|l|}{ RFS } & \multirow{2}{*}{$\begin{array}{c}\text { Expression } \\
\text { associates with } \\
\text { bad prognosis }\end{array}$} \\
\hline & & $\begin{array}{l}\text { High } \\
\text { level }\end{array}$ & $\begin{array}{l}\text { Low } \\
\text { level }\end{array}$ & HR (95\% CI) & $P$ & $\begin{array}{l}\text { HR }(95 \% \\
\text { CI) }\end{array}$ & $P$ & $\begin{array}{l}\text { HR }(95 \% \\
\text { CI) }\end{array}$ & $P$ & \\
\hline Neal 2010 & 210 & 17 & 14 & $2.41(0.65-8.96)$ & 0.189 & - & - & - & - & High \\
\hline Slaby 2010 & $106 \mathrm{~b}$ & 19 & 19 & - & - & - & - & $\begin{array}{c}0.37(0.15- \\
0.92)\end{array}$ & 0.032 & Low \\
\hline Cui 2012 & $99 \mathrm{a}$ & 11 & 29 & $0.27(0.11-0.64)$ & 0.003 & - & - & - & - & Low \\
\hline $\begin{array}{l}\text { Faragalla } \\
2012\end{array}$ & 21 & 48 & 40 & $1.97(1.04-3.73)$ & 0.036 & $\begin{array}{c}2.15 \\
(1.16- \\
3.98)^{\mathrm{D}}\end{array}$ & 0.014 & - & - & High \\
\hline Hirata 2012 & 1826 & 23 & 23 & $0.24(0.07-0.90)$ & 0.0347 & - & - & $\begin{array}{c}0.30(0.12- \\
0.75)\end{array}$ & 0.0104 & Low \\
\hline $\begin{array}{l}\text { Zaman } \\
2012\end{array}$ & 21 & 30 & 6 & $\begin{array}{c}4.50(1.16- \\
17.49)\end{array}$ & 0.030 & - & - & - & - & High \\
\hline \multirow[t]{2}{*}{ Goto 2013} & 486 & 112 & 38 & - & - & $\begin{array}{c}1.13(0.60- \\
2.11)^{\mathrm{C}}\end{array}$ & 0.7062 & - & - & High \\
\hline & 486 & 34 & 12 & - & - & $\begin{array}{c}4.33(1.45- \\
18.71)^{\mathrm{C}}\end{array}$ & 0.0064 & - & - & High \\
\hline Hirata 2013 & $1260 \mathrm{~b}$ & 21 & 22 & $\begin{array}{c}6.03(1.22- \\
28.89)\end{array}$ & 0.0278 & - & - & - & - & High \\
\hline $\begin{array}{l}\text { Khella } \\
2013\end{array}$ & 215 & 165 & 53 & $0.55(0.37-0.82)$ & 0.0032 & - & - & - & - & Low \\
\hline Li 2013 & 217 & 9 & 34 & $0.24(0.08-0.71)$ & $<0.01$ & - & - & - & - & Low \\
\hline $\begin{array}{l}\text { McCormick } \\
2013\end{array}$ & 210 & 23 & 23 & $0.33(0.15-0.72)$ & 0.005 & - & - & - & - & Low \\
\hline \multirow[t]{2}{*}{$\begin{array}{l}\text { Shinmei } \\
2013\end{array}$} & 155 & 69 & 68 & - & - & $\begin{array}{c}0.90(0.52- \\
1.55)^{\mathrm{C}}\end{array}$ & 0.7001 & - & - & Low \\
\hline & 155 & 21 & 22 & - & - & \begin{tabular}{|c|}
$0.47(0.23-$ \\
$0.94)^{\mathrm{C}}$
\end{tabular} & 0.0337 & - & - & Low \\
\hline Wang 2013 & 100 & 60 & 36 & $3.6(1.8-5.2)$ & 0.01 & $\begin{array}{c}2.4(1.4- \\
4.9)^{\mathrm{C}}\end{array}$ & 0.02 & - & - & High \\
\hline $\begin{array}{l}\text { Wotschofsky } \\
2013\end{array}$ & 210 & 43 & 44 & - & - & - & - & $\begin{array}{c}0.39(0.12- \\
1.23)\end{array}$ & 0.109 & Low \\
\hline Zhao 2013 & 187 & 18 & 68 & $0.36(0.17-0.78)$ & $<0.01$ & - & - & - & - & Low \\
\hline Chen 2014 & $\begin{array}{c}129- \\
3 p\end{array}$ & - & - & $0.31(0.11-0.93)$ & 0.037 & $\begin{array}{c}0.32(0.11- \\
0.94)^{\mathrm{D}}\end{array}$ & 0.039 & - & - & Low \\
\hline Fu 2014 & $125 b$ & - & - & - & - & $\begin{array}{c}1.99(1.10- \\
3.76)^{\mathrm{C}}\end{array}$ & 0.024 & $\begin{array}{c}2.40(1.37- \\
4.78)\end{array}$ & 0.005 & High \\
\hline \multirow[t]{2}{*}{$\begin{array}{l}\text { Ishihara } \\
2014\end{array}$} & $23 b$ & 31 & 30 & $0.24(0.07-0.79)$ & 0.0183 & - & - & - & - & Low \\
\hline & $27 b$ & 31 & 30 & $0.26(0.08-0.85)$ & 0.0253 & - & - & - & - & Low \\
\hline \multirow[t]{2}{*}{$\begin{array}{l}\text { Teixeira } \\
2014\end{array}$} & 221 & 11 & 32 & $\begin{array}{c}4.20(1.21- \\
14.59)\end{array}$ & 0.024 & $\begin{array}{c}10.7(1.33- \\
85.65)^{\mathrm{C}}\end{array}$ & 0.026 & - & - & High \\
\hline & 222 & 11 & 32 & $1.85(0.71-4.82)$ & 0.208 & - & - & - & - & High \\
\hline
\end{tabular}

(Continued) 


\begin{tabular}{|c|c|c|c|c|c|c|c|c|c|c|}
\hline \multirow[t]{2}{*}{ Study } & \multirow[t]{2}{*}{ miR } & \multicolumn{2}{|c|}{ Case number } & \multicolumn{2}{|l|}{ OS } & \multicolumn{2}{|c|}{ CSS/DFS } & \multicolumn{2}{|l|}{ RFS } & \multirow{2}{*}{$\begin{array}{c}\text { Expression } \\
\text { associates with } \\
\text { bad prognosis }\end{array}$} \\
\hline & & $\begin{array}{l}\text { High } \\
\text { level }\end{array}$ & $\begin{array}{l}\text { Low } \\
\text { level }\end{array}$ & HR $(95 \%$ CI $)$ & $P$ & $\begin{array}{c}\text { HR }(95 \% \\
\text { CI) }\end{array}$ & $P$ & $\begin{array}{l}\text { HR }(95 \% \\
\text { CI) }\end{array}$ & $P$ & \\
\hline \multirow[t]{2}{*}{$\begin{array}{l}\text { Vergho } \\
2014\end{array}$} & 21 & 43 & 60 & - & - & $\begin{array}{c}6.47(1.84- \\
22.73)^{\mathrm{C}}\end{array}$ & 0.0008 & - & - & High \\
\hline & 126 & 31 & 72 & - & - & $\begin{array}{c}0.20(0.07- \\
0.58)^{\mathrm{C}}\end{array}$ & 0.0032 & - & - & Low \\
\hline \multirow[t]{4}{*}{$\begin{array}{l}\text { Vergho } \\
2014\end{array}$} & 21 & - & - & - & - & $\begin{array}{c}3.52(1.93- \\
6.44)^{\mathrm{C}}\end{array}$ & 0.0001 & - & - & High \\
\hline & 126 & - & - & - & - & $\begin{array}{c}0.50(0.28- \\
0.87)^{\mathrm{C}}\end{array}$ & 0.012 & - & - & Low \\
\hline & 210 & - & - & - & - & $\begin{array}{c}1.14(0.91- \\
1.44)^{\mathrm{C}}\end{array}$ & 0.231 & - & - & High \\
\hline & 221 & - & - & - & - & $\begin{array}{c}0.71(0.45- \\
1.14)^{\mathrm{C}}\end{array}$ & 0.139 & - & - & Low \\
\hline Zhao 2014 & 630 & 58 & 34 & $3.02(2.07-5.73)$ & 0.016 & - & - & - & - & High \\
\hline Ge 2015 & 210 & 29 & 29 & $\begin{array}{c}6.50(1.76- \\
24.00)\end{array}$ & 0.005 & - & - & $\begin{array}{c}26.01(2.42- \\
279.1)\end{array}$ & 0.007 & High \\
\hline \multirow[t]{2}{*}{$\begin{array}{l}\text { Khella } \\
2015\end{array}$} & 126 & 210 & 50 & $0.40(0.19-0.86)$ & 0.019 & $\begin{array}{c}0.30(0.18- \\
0.50)^{\mathrm{D}}\end{array}$ & $\begin{array}{c}< \\
0.001\end{array}$ & - & - & Low \\
\hline & 126 & - & - & $0.48(0.29-0.80)$ & 0.0035 & - & - & - & - & Low \\
\hline $\begin{array}{l}\text { Samaan } \\
2015\end{array}$ & 210 & 112 & 150 & $\begin{array}{c}2.46(1.20 \\
-5.04)\end{array}$ & 0.014 & $\begin{array}{c}1.82 \\
(1.11- \\
3.00)^{\mathrm{D}}\end{array}$ & 0.018 & - & - & High \\
\hline \multirow[t]{2}{*}{ Tang 2015} & 21 & - & - & - & - & $\begin{array}{c}6.46(1.35- \\
30.94)^{\mathrm{C}}\end{array}$ & 0.02 & - & - & High \\
\hline & 210 & - & - & - & - & $\begin{array}{c}3.27(1.01- \\
10.59)^{\mathrm{C}}\end{array}$ & 0.05 & - & - & High \\
\hline Zhao 2015 & 497 & 38 & 48 & $2.58(1.69-6.36)$ & $<0.001$ & - & - & - & - & High \\
\hline
\end{tabular}

OS = overall survival; CSS = cancer specific survival; DFS = disease free survival; RFS = recurrence free survival;

$\mathrm{HR}=$ hazard ratio;

${ }^{\mathrm{C}} \mathrm{CSS}$;

${ }^{D}$ DFS.

MiR-21 is one of the most extensively studied cancer-related miRs and might be the most relevant oncogenic factor in most cancers [53-55]. Increased miR-21 expression enhances tumor growth, migration, and invasion, and reduces sensitivity to chemotherapy through modulating various target genes [21, 22, 56]. Cancer patients with higher miR-21 expression levels always suffered from a poorer prognostic outcome [57], which is consistent with our findings. There are a number of molecular mechanisms that could explain this relationship. Dey et al. [58] showed that miR-21 mediated the post-transcriptional regulation of phosphatase and tensin homolog (PTEN) that in turn increased canonical oncogenic Akt/TORC1 signaling to drive renal cancer cell proliferation and invasion. Furthermore, miR-21 promoted renal cancer cell hyperplasia and contributed to tumor cell transformation and metastasis, but also posttranscriptionally down-regulated the expression of the
PDCD4 tumor suppressor gene [59]. MiR-126 is located in intron 7 of the epidermal growth factor-like protein 7 gene (EGFL7) on chromosome 9 [29], and is down regulated in various cancer types including breast, gastric, and prostate cancer, and RCC [26]. In the latter, miR-126 features in the molecular classification of different tumor sub-types [60]. More recently, miR-126 down-regulation has been linked to RCC progression, and has been shown to act as a tumor suppressor in various cancer types including RCC through regulating target genes such as CRK, VEGF, and EGFL7 in cancer cells [61, 62]. Khella et al. [29] found that miR-126 is down-regulated in metastatic compared to primary ccRCC, and in tumors with a higher stage or grade. Their target prediction and pathway analysis showed that miR-126 can regulate key molecules and critical pathways involved in ccRCC tumor development and progression, including the IGF1R, BCL2, HIF-1, VEGF, mTOR, and PI3K-Akt signaling pathways. 


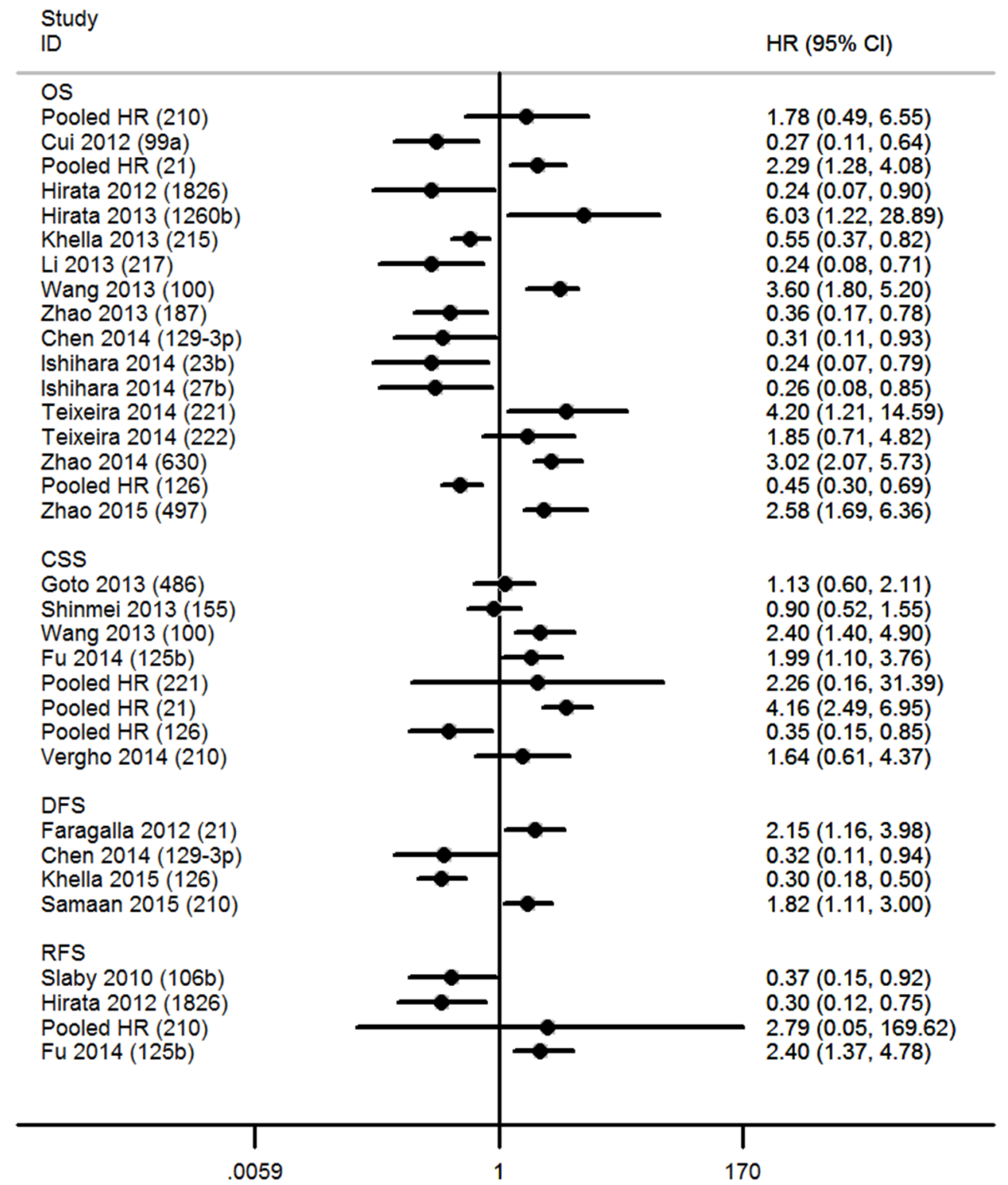

Figure 2: Hazard ratios (HR) of miRs. The point estimate is bounded by a $95 \%$ confidence interval (CI), and the perpendicular line represents no increased risk for the outcome. OS = overall survival; CSS = cancer specific survival; DFS = disease free survival; RFS = recurrence free survival.

Hypoxia is an important pathophysiological process in solid cancers including RCC, and has been shown to influence miR-210 expression. MiR-210 is up-regulated in renal cancer [63-65], and is included in a miR-based classification system of this disease [66]. In ccRCC, VHL gene mutations lead to the up-regulation of HIF-1 and HIF-2, with subsequent overexpression of miR-210 [23]. Conversely, miR-210 was also shown to regulate HIF-1 protein and other target genes in RCC, affecting carcinogenesis-related processes such as cell migration and invasion, cell survival, apoptosis, mitochondrial metabolism, angiogenesis, and DNA repair [67, 68]. In addition, studies have shown that miR-210 targets the iron sulfur cluster homologue gene (ISCU), the product of which acts as a scaffold protein for the formation of iron sulfur (Fe-S) clusters [20, 23]. However, reports of an association between increased miR-210 expression and prognosis in RCC are inconsistent [20, 23, 24, 27, 28, 30, $31]$, and hence larger, multicenter studies are needed to address this.

Recent studies have reported tumor-specific miR221 expression that is mediated by intricate regulatory mechanisms, and several target genes of miR-221 influence tumorigenesis and progression. These include the cell cycle regulators $\mathrm{p} 27 \mathrm{Kip} 1$ and $\mathrm{p} 57 \mathrm{Kip} 2$, which are repressed by miR-221 in multiple cancers to induce tumor cell proliferation. MiR-221 also directly inhibits the posttranscriptional expression of metallopeptidase inhibitor 

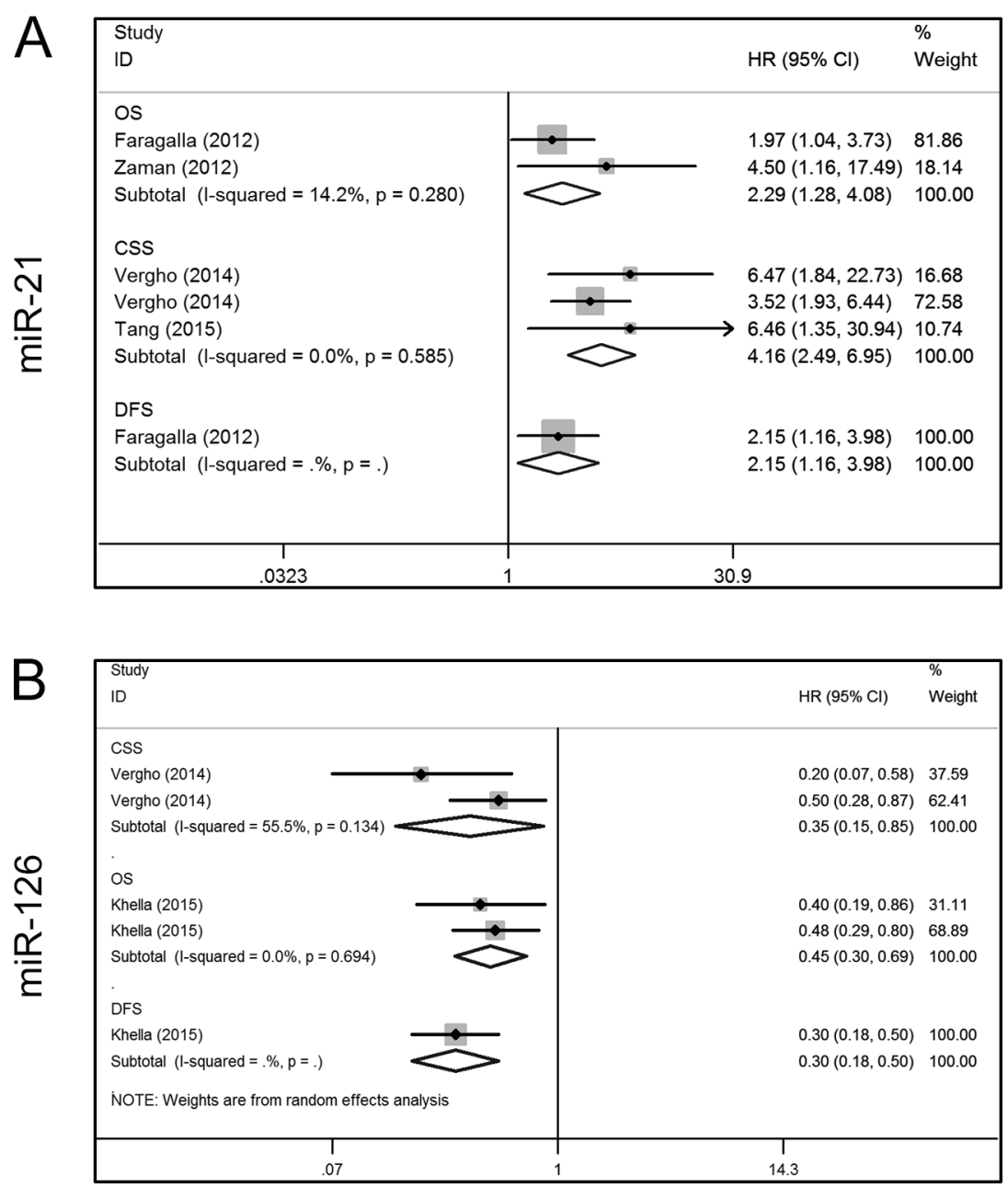

Figure 3: Forest plots of studies evaluating hazard ratios of aberrant miR-21 and mir-126 expression. A. miR-21, OS, CSS, DFS; B. miR-126, CSS, OS, DFS. OS = overall survival; CSS = cancer specific survival; DFS = disease free survival; HR = hazard ratio.

3 (TIMP3), an inhibitor of matrix metalloproteinases (MMPs), and plays an important role in promoting the invasion of human gliomas. The oncogenic effect of miR221 is also mediated by PTEN [69]. In renal tumors, mir221 is included in a miR-based classification system [66]. Its expression is activated by EGFR signaling, and it can subsequently modulate metastasis in RCC. Teixeira et al. [25] found that plasma miR-221 levels varied during RCC development, and that increased levels were associated with a shorter OS.

In addition to the above, we also systematically investigated the relationship of other miRs with RCC prognosis in this study. These relationships, as well as the possible roles of other miRs in RCC progression are summarized in Figure 2 and Table 3.

Some limitations need be considered in the interpretation of the results of the current study. First, although 27 studies involving 2578 patients were included in this systematic review, most of them addressed diverse miRs and used different follow-up endpoints. Only four
miRs (miR-21, miR-126, miR-210, and miR-221) were identified by at least two studies, and these also used different outcome assessments. Thus, most of meta-analyses in our study only contain two or three records, and large prospective studies are therefore needed to confirm our findings and allow rigorous conclusions to be made. Further, due to inadequate data, we did not evaluate publication bias. The lack of these analyses may partly affect the interpretation of the results and make them less reliable. Second, marked study heterogeneity was seen in some analyses. The heterogeneity of the subjects was probably due to differences in factors such as the patients' baseline characteristics (ethnicity, nationality, gender, age, and tumor stage and grade), different assay methods, diverse cut-off values for miR expression, the way samples were prepared and preserved (i.e. paraffin fixed, formalin fixed, freshly frozen tumors or blood), treatment, and duration of followup. The method of extracting the HRs of these studies may also have introduced heterogeneity. Seven of the studies included in the systematic review did not report an HR or 

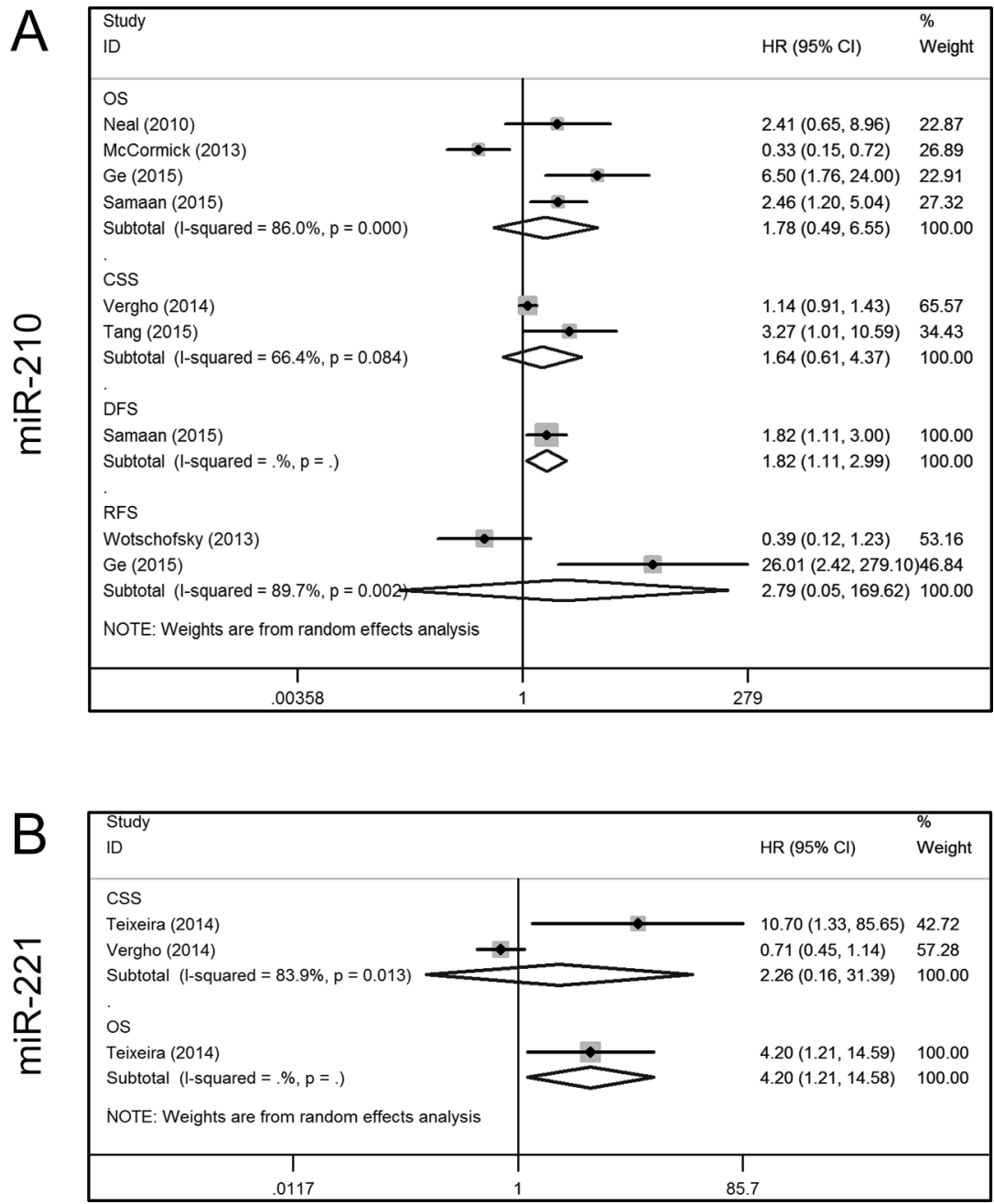

Figure 4: Forest plots of studies evaluating hazard ratios of aberrant miR-210 and mir-221 expression. A. miR-210, OS, CSS, DFS, RFS; B. miR-221, CSS, OS. OS = overall survival; CSS = cancer specific survival; DFS = disease free survival; RFS = recurrence free survival; $\mathrm{HR}=$ hazard ratio.

other survival related statistics. Therefore, we had to extract the required data using a Kaplan-Meier graph that was prone to error, even when two independent reviewers extracted the data. The calculated HRs may thus not be as dependable as those retrieved directly from reported statistics. Finally, a number of unavoidable limitations exist. All meta-analyses are affected by the quality of their component studies; the fact that research with statistically significant results is potentially more likely to be submitted and published than work with null or non-significant results could compromise the validity of such analyses [70]. Furthermore, the current meta-analysis of published studies does not have the benefit of currently unpublished data [71]. Recently, circulating markers have become more acceptable than tissue markers because they can be evaluated before surgery and be monitored throughout the life of the patient. Further studies are needed to establish the prognostic value of miR serum levels [25]. It should be noted that some studies developed combined expression signatures of multiple miRs
$[19,72,73]$, which requires a robust validation strategy. Furthermore, the model has to be validated in a separate experiment using an independent patient cohort. Hence, developing a new molecular signature by using diverse miRs and investigating their efficacy may be useful.

Despite the limitations described above, our comprehensive systematic review and meta-analysis reveals that miRs, especially miR-21 and miR-126, could be promising, convenient and potentially non-invasive prognostic markers in RCC, and could allow monitoring for cancer progression or recurrence. These miRs may also be useful therapeutic targets in RCC. However, more studies are needed to clarify the prognostic value of these novel biomarkers and address possible discrepancies.

\section{MATERIALS AND METHODS}

This meta-analysis was conducted following the guidelines of the Meta-analysis of Observational Studies 
Table 3: Summary of miRs with altered expression, their potential targets and pathways entered this study

\begin{tabular}{|c|c|c|c|c|}
\hline microRNA & Expression & Potential target & Pathway & Reference \\
\hline $\operatorname{miR}-210$ & Up & ISCU1/2, HIF & VHL/HIF/hypoxia pathway & $20,23,24,27,28,30,31$ \\
\hline $\operatorname{miR}-21$ & Up & $\begin{array}{l}\text { P53, TGF- } \beta \text {, VHL, EGLN1, } \\
\text { PTEN, TSC1, TSC2, PDCD4, }\end{array}$ & $\begin{array}{l}\text { Cell cycle control/ proliferation, } \\
\text { migration and invasion, } \\
\text { mitochondrial apoptosis pathway }\end{array}$ & $21,22,26,27,31$ \\
\hline miR-486 & Up & PTEN, OLFM4, FOXO1 & Cell adhesion and migration & 45 \\
\hline miR-1260b & Up & sFRP1, Dkk2, Smad4 & $\begin{array}{l}\text { Cell proliferation, apoptosis, } \\
\text { invasion }\end{array}$ & 32 \\
\hline miR-100 & Up & mTOR & Cell proliferation & 33 \\
\hline $\operatorname{miR}-125 b$ & Up & E2F3, P53, BAK1, MMP9 & $\begin{array}{l}\text { Cell growth, apoptosis, } \\
\text { metastasis }\end{array}$ & 34 \\
\hline miR-221 & Up & $\begin{array}{l}\text { PTEN, TIMP3, c-Kit, p21, p53, } \\
\text { p57 }\end{array}$ & $\begin{array}{l}\text { Cell cycle, proliferation, } \\
\text { apoptosis, migration, invasion, } \\
\text { EMT, EGFR signaling pathway }\end{array}$ & 25,27 \\
\hline miR-222 & Up & PTEN, TIMP3, c-Kit, p21 & $\begin{array}{l}\text { Cell cycle, migration, invasion, } \\
\text { EMT }\end{array}$ & 25 \\
\hline $\operatorname{miR}-630$ & Up & IGF-1R & Cell death and apoptosis & 35 \\
\hline $\operatorname{miR}-497$ & Up & IGF-1R & $\begin{array}{l}\text { Cell proliferation, migration, } \\
\text { invasion }\end{array}$ & 36 \\
\hline miR-106b & Down & TGF- $\beta$ signaling & TGF- $\beta$ signaling & 37 \\
\hline miR-99a & Down & mTOR & $\begin{array}{l}\text { Cell growth/cycle control, } \\
\text { migration and invasion, mTOR } \\
\text { pathway }\end{array}$ & 38 \\
\hline miR-1826 & Down & CTNNB1, MEK1 & $\begin{array}{l}\text { Cell proliferation, invasion, } \\
\text { migration, apoptosis }\end{array}$ & 39 \\
\hline miR-215 & Down & MDM2, ZEB2, TYMS & $\begin{array}{l}\text { Cell migration, invasion, } \\
\text { proliferation }\end{array}$ & 40 \\
\hline miR-217 & Down & SirT1, KRAS & Cell proliferation, migration & 41 \\
\hline miR-155 & Down & SOCS1, SHIP1, TP53INP1 & $\begin{array}{l}\text { Apoptosis-related signaling, } \\
\text { hypoxia pathway }\end{array}$ & 46 \\
\hline miR-187 & Down & B7-H3, Dab2 & Cell growth, migration, EMT & 42 \\
\hline miR-129-3p & Down & SOX4, p-FaK, MMP2, MMP9 & Cell migration, invasion & 43 \\
\hline $\mathrm{miR}-23 \mathrm{~b} / 27 \mathrm{~b}$ & Down & cytokine interaction pathway & $\begin{array}{l}\text { Cell proliferation, migration and } \\
\text { invasion }\end{array}$ & 44 \\
\hline $\operatorname{miR}-126$ & Down & $\begin{array}{l}\text { SPRED1, IGF1R, BCL2, CRK, } \\
\text { CCNE2, PIK3R2, EGFL7 }\end{array}$ & $\begin{array}{l}\text { Apoptosis, HIF-1, VEGF, } \\
\text { mTOR, and PI3K-Akt signaling } \\
\text { pathways }\end{array}$ & $26,27,29$ \\
\hline
\end{tabular}

$\mathrm{HIF}=$ hypoxia inducible factor; $\mathrm{PTEN}=$ phosphatase and tensin homologue; $\mathrm{TGF}=$ transforming growth factor; $\mathrm{mTOR}=$ mammalian target of rapamycin; TSC = tuberous sclerosis; $\mathrm{MMP}=$ matrix metalloproteinase; TIMP $=$ tissue inhibitor of metalloproteinase; EMT = epithelial-to-mesenchymal transition; EGFR = epidermal growth factor receptor; IGF $=$ insulinlike growth factor; VEGF = vascular endothelial growth factor. 
in Epidemiology group (MOOSE) [74] and Preferred Reporting Items for Systematic Reviews and Metaanalysis (PRISMA) criteria [75].

\section{Search strategy}

A literature search was performed on Pubmed and Embase for studies that analyzed associations between miRs and prognosis in RCC patients on April 15, 2015, using the following search strategy: (microRNA OR miRNA OR miR) AND (cancer OR tumor OR neoplasm OR malignant OR metastasis OR carcinoma OR renal cell carcinoma OR RCC) AND (renal or kidney) AND (prognosis OR prognostic OR survival OR outcome OR mortality). Additionally, we manually screened the references from the relevant literature, including all of the identified studies, reviews, and editorials.

\section{Eligibility criteria}

The main criteria considered in including a study were investigating the prognosis of RCC, measuring the expression of specific miRs in tissue or serum and studying their association with survival outcome. Survival outcome was further explored considering Hazard ratio (HR) with Confidence interval (CI), HR with $P$ value, Kaplan-Meier curves or obtaining the required data by contacting correspondent author. Articles were excluded if they (1) were not written in English; (2) were case reports, letters, commentaries, meeting records or review articles; (3) had sample of fewer than 30 cases; (4) concerned genetic alterations of a miR including polymorphisms or methylation patterns; (5) calculated hazard ratios (HRs) based on multiple miR; (6) lacked sufficient data for estimating HRs and their $95 \%$ confidence intervals (CIs). When duplicate studies were retrieved, we included the most informative and recent article.

Thereafter, the papers that fulfilled all selection criteria were processed for data extraction. Three individual researchers (L. Gu., H. Li., and L. Chen) independently assessed eligibility of the retrieved articles. Discrepancies were resolved by discussion.

\section{Quality assessment}

The quality of all the included studies was systematically assessed according to the following checklist based on the Dutch Cochrane Centre represented by MOOSE for epidemiologic studies [74]: (1) clearly defined study design; (2) clearly described study population (Country); (3) sufficiently large sample $(N>30$ for the current study); (4) clearly described outcome assessment by representing it in overall survival (OS), cancer-specific survival (CSS), disease-free survival (DFS) or recurrencefree survival (RFS); (5) clear definition of measurement of miR (quantitative real-time polymerase chain reaction
(qRT-PCR) (TaqMan assay or stem-loop primer assay) or in situ hybridization (ISH), hybridized oligonucleotide microarray (oligoarray)); (6) clear definition of cut-off; and (7) sufficiently long follow-up.

To assure the quality of this meta-analysis, studies were excluded if they do not meet these seven criteria.

\section{Data extraction}

Data were extracted independently by three investigators (L. Gu., H. Li., and L. Chen), who used a predefined sheet to retrieve information about all studies that qualified for final inclusion. Data sheets were designed according to previous studies focusing on similar issue and PRISMA guideline $[49,75]$. The following data were extracted: (1) publication information: first author's last name, year of publication and study design; (2) patients' characteristics: population study, investigated microRNAs, number of participants, stage of disease, detected sample and follow-up duration; (3) miR expression measurement and cut-off value; and (4) HRs of elevated miRs for OS, CSS, DFS, RFS, as well as their $95 \%$ CIs and $P$ values. If available, the HRs with their $95 \%$ CIs and $P$ values were collected from the original article or the correspondent author. If not, we calculated HRs and their $95 \%$ CIs using the data of observed events, the data of samples in each group or the data provided by the authors. If only KaplanMeier curves were available, we extracted data from the graphical survival plots and estimated the HRs. All the calculations mentioned above were based on the methods illustrated by Parmar et al. [76] and Tierney et al [77].

\section{Statistical analysis}

A test of heterogeneity of combined HRs was conducted using Cochran's Q test and Higgins $I$-squared statistic. A $P$ value of less than 0.1 was considered significant. $I^{2}$ values of $>50 \%$ indicate heterogeneity among studies. A random effect model was applied if heterogeneity was observed $(P<0.1)$, while the fixed effect model was used in the absence of between-study heterogeneity $(P>0.1)$. An observed HR $>1$ implied a worse survival for the group with elevated miR expression. Conversely, an observed HR $<1$ implied a worse survival for the group with decreased miR expression. We pooled HRs of the studies by using Stata 12.0 software (StatCorp, College Station, TX, USA).

\section{ACKNOWLEDGMENTS AND FUNDING}

This work was financially supported by the People's Republic of China and the National High Technology Research and Development Program ("863"Program) of China: the screening and clinical validation of characteristic protein biomarkers in renal cancer based on a large-scale biobank (2014AA020607). 


\section{CONFLICTS OF INTEREST}

The authors declare no conflict of interest.

\section{REFERENCES}

1. Siegel R, Ma J, Zou Z, Jemal A. Cancer statistics. CA Cancer J Clin. 2014; 64:9-29.

2. Murai M, Oya M. Renal cell carcinoma: etiology, incidence and epidemiology. Curr Opin Urol. 2004; 14:229-233.

3. Cohen HT, McGovern FJ. Renal-cell carcinoma. N Engl J Med. 2005; 353:2477-2490.

4. Crispen PL, Breau RH, Allmer C, Lohse CM, Cheville JC, Leibovich BC, Blute ML. Lymph node dissection at the time of radical nephrectomy for high-risk clear cell renal cell carcinoma: indications and recommendations for surgical templates. Eur Urol. 2011; 59:18-23.

5. Moch H, Artibani W, Delahunt B, Ficarra V, Knuechel R, Montorsi F, Patard JJ, Stief CG, Sulser T, Wild PJ. Reassessing the current UICC/AJCC TNM staging for renal cell carcinoma. Eur Urol. 2009; 56:636-643.

6. Delahunt B, Srigley JR, Montironi R, Egevad L. Advances in renal neoplasia: recommendations from the 2012 International Society of Urological Pathology Consensus Conference. Urology. 2014; 83:969-974.

7. Li M, Wang Y, Song Y, Bu R, Yin B, Fei X, Guo Q, Wu B. MicroRNAs in renal cell carcinoma: A systematic review of clinical implications (Review). Oncol Rep. 2015; 33:1571-1578.

8. Bartel DP. MicroRNAs: target recognition and regulatory functions. Cell. 2009; 136:215-233.

9. Lee RC, Feinbaum RL, Ambros V. The C. elegans heterochronic gene lin-4 encodes small RNAs with antisense complementarity to lin-14. Cell. 1993; 75:843-854.

10. Croce CM. Causes and consequences of microRNA dysregulation in cancer. Nat Rev Genet. 2009; 10:704-714.

11. White NM, Fatoohi E, Metias M, Jung K, Stephan C, Yousef GM. Metastamirs: a stepping stone towards improved cancer management. Nat Rev Clin Oncol. 2011; $8: 75-84$

12. Deng G, Sui G. Noncoding RNA in oncogenesis: a new era of identifying key players. Int J Mol Sci. 2013; 14:18319-18349.

13. Schetter AJ, Leung SY, Sohn JJ, Zanetti KA, Bowman ED, Yanaihara N, Yuen ST, Chan TL, Kwong DL, Au GK, Liu CG, Calin GA, Croce CM, Harris CC. MicroRNA expression profiles associated with prognosis and therapeutic outcome in colon adenocarcinoma. Jama. 2008; 299:425-436.

14. Yanaihara N, Caplen N, Bowman E, Seike M, Kumamoto K, Yi M, Stephens RM, Okamoto A, Yokota J, Tanaka T, Calin GA, Liu CG, Croce CM, Harris CC. Unique microRNA molecular profiles in lung cancer diagnosis and prognosis. Cancer Cell. 2006; 9:189-198.
15. Iorio MV, Ferracin M, Liu CG, Veronese A, Spizzo R, Sabbioni S, Magri E, Pedriali M, Fabbri M, Campiglio M, Menard S, Palazzo JP, Rosenberg A, Musiani P, Volinia S, Nenci I, et al. MicroRNA gene expression deregulation in human breast cancer. Cancer Res. 2005; 65:7065-7070.

16. Iorio MV, Visone R, Di Leva G, Donati V, Petrocca F, Casalini P, Taccioli C, Volinia S, Liu CG, Alder H, Calin GA, Menard S, Croce CM. MicroRNA signatures in human ovarian cancer. Cancer Res. 2007; 67:8699-8707.

17. Heinzelmann J, Henning B, Sanjmyatav J, Posorski N, Steiner T, Wunderlich H, Gajda MR, Junker K. Specific miRNA signatures are associated with metastasis and poor prognosis in clear cell renal cell carcinoma. World J Urol. 2011; 29:367-373.

18. Heinzelmann J, Unrein A, Wickmann U, Baumgart S, Stapf M, Szendroi A, Grimm MO, Gajda MR, Wunderlich H, Junker K. MicroRNAs with prognostic potential for metastasis in clear cell renal cell carcinoma: a comparison of primary tumors and distant metastases. Ann Surg Oncol. 2014; 21:1046-1054.

19. Ge YZ, Wu R, Xin H, Zhu M, Lu TZ, Liu H, Xu Z, Yu P, Zhao YC, Li MH, Hu ZK, Zhao Y, Zhong B, Xu X, Zhou LH, $\mathrm{Xu} \mathrm{LW}$, et al. A tumor-specific microRNA signature predicts survival in clear cell renal cell carcinoma. J Cancer Res Clin Oncol. 2015.

20. Neal CS, Michael MZ, Rawlings LH, Van der Hoek MB, Gleadle JM. The VHL-dependent regulation of microRNAs in renal cancer. BMC Med. 2010; 8:64.

21. Faragalla H, Youssef YM, Scorilas A, Khalil B, White NM, Mejia-Guerrero S, Khella H, Jewett MA, Evans A, Lichner Z, Bjarnason G, Sugar L, Attalah MI, Yousef GM. The clinical utility of miR-21 as a diagnostic and prognostic marker for renal cell carcinoma. J Mol Diagn. 2012; 14:385-392.

22. Zaman MS, Shahryari V, Deng G, Thamminana S, Saini S, Majid S, Chang I, Hirata H, Ueno K, Yamamura S, Singh K, Tanaka Y, Tabatabai ZL, Dahiya R. Up-regulation of microRNA-21 correlates with lower kidney cancer survival. PLoS One. 2012; 7:e31060.

23. McCormick RI, Blick C, Ragoussis J, Schoedel J, Mole DR, Young AC, Selby PJ, Banks RE, Harris AL. miR-210 is a target of hypoxia-inducible factors 1 and 2 in renal cancer, regulates ISCU and correlates with good prognosis. Br J Cancer. 2013; 108:1133-1142.

24. Wotschofsky Z, Busch J, Jung M, Kempkensteffen C, Weikert S, Schaser KD, Melcher I, Kilic E, Miller K, Kristiansen G, Erbersdobler A, Jung K. Diagnostic and prognostic potential of differentially expressed miRNAs between metastatic and non-metastatic renal cell carcinoma at the time of nephrectomy. Clin Chim Acta. 2013; 416:5-10.

25. Teixeira AL, Ferreira M, Silva J, Gomes M, Dias F, Santos JI, Mauricio J, Lobo F, Medeiros R. Higher circulating expression levels of miR-221 associated with poor overall survival in renal cell carcinoma patients. Tumour Biol. 2014; 35:4057-4066. 
26. Vergho D, Kneitz S, Rosenwald A, Scherer C, Spahn M, Burger M, Riedmiller H, Kneitz B. Combination of expression levels of miR-21 and miR-126 is associated with cancer-specific survival in clear-cell renal cell carcinoma. BMC Cancer. 2014; 14:25.

27. Vergho DC, Kneitz S, Kalogirou C, Burger M, Krebs M, Rosenwald A, Spahn M, Loser A, Kocot A, Riedmiller H, Kneitz B. Impact of miR-21, miR-126 and miR-221 as prognostic factors of clear cell renal cell carcinoma with tumor thrombus of the inferior vena cava. PLoS One. 2014; 9:e109877.

28. Ge YZ, Xin H, Lu TZ, Xu Z, Yu P, Zhao YC, Li MH, Zhao Y, Zhong B, Xu X, Zhou LH, Wu R, Xu LW, Wu JP, Li WC, Zhu JG, et al. MicroRNA expression profiles predict clinical phenotypes and prognosis in chromophobe renal cell carcinoma. Sci Rep. 2015; 5:10328.

29. Khella HW, Scorilas A, Mozes R, Mirham L, Lianidou E, Krylov SN, Lee JY, Ordon M, Stewart R, Jewett MA, Yousef GM. Low Expression of miR-126 Is a Prognostic Marker for Metastatic Clear Cell Renal Cell Carcinoma. Am J Pathol. 2015; 185:693-703.

30. Samaan S, Khella HW, Girgis A, Scorilas A, Lianidou E, Gabril M, Krylov SN, Jewett M, Bjarnason GA, El-Said H, Yousef GM. miR-210 Is a Prognostic Marker in Clear Cell Renal Cell Carcinoma. J Mol Diagn. 2015; 17:136-144.

31. Tang K, Xu H. Prognostic value of meta-signature miRNAs in renal cell carcinoma: an integrated miRNA expression profiling analysis. Sci Rep. 2015; 5:10272.

32. Hirata H, Ueno K, Nakajima K, Tabatabai ZL, Hinoda Y, Ishii N, Dahiya R. Genistein downregulates onco-miR$1260 \mathrm{~b}$ and inhibits Wnt-signalling in renal cancer cells. $\mathrm{Br}$ J Cancer. 2013; 108:2070-2078.

33. Wang G, Chen L, Meng J, Chen M, Zhuang L, Zhang L. Overexpression of microRNA-100 predicts an unfavorable prognosis in renal cell carcinoma. Int Urol Nephrol. 2013; 45:373-379.

34. Fu Q, Liu Z, Pan D, Zhang W, Xu L, Zhu Y, Liu H, Xu J. Tumor miR-125b predicts recurrence and survival of patients with clear-cell renal cell carcinoma after surgical resection. Cancer Sci. 2014; 105:1427-1434.

35. Zhao JJ, Chen PJ, Duan RQ, Li KJ, Wang YZ, Li Y. Up-regulation of miR-630 in clear cell renal cell carcinoma is associated with lower overall survival. Int J Clin Exp Pathol. 2014; 7:3318-3323.

36. Zhao X, Zhao Z, Xu W, Hou J, Du X. Down-regulation of miR-497 is associated with poor prognosis in renal cancer. Int J Clin Exp Pathol. 2015; 8:758-764.

37. Slaby O, Jancovicova J, Lakomy R, Svoboda M, Poprach A, Fabian P, Kren L, Michalek J, Vyzula R. Expression of miRNA-106b in conventional renal cell carcinoma is a potential marker for prediction of early metastasis after nephrectomy. J Exp Clin Cancer Res. 2010; 29:90.

38. Cui L, Zhou H, Zhao H, Zhou Y, Xu R, Xu X, Zheng L, Xue Z, Xia W, Zhang B, Ding T, Cao Y, Tian Z, Shi Q, He X.
MicroRNA-99a induces G1-phase cell cycle arrest and suppresses tumorigenicity in renal cell carcinoma. BMC Cancer. 2012; 12:546.

39. Hirata $H$, Hinoda $Y$, Ueno $K$, Nakajima $K$, Ishii $N$, Dahiya R. MicroRNA-1826 directly targets beta-catenin (CTNNB1) and MEK1 (MAP2K1) in VHL-inactivated renal cancer. Carcinogenesis. 2012; 33:501-508.

40. Khella HW, Bakhet M, Allo G, Jewett MA, Girgis AH, Latif A, Girgis H, Von Both I, Bjarnason GA, Yousef GM. miR-192, miR-194 and miR-215: a convergent microRNA network suppressing tumor progression in renal cell carcinoma. Carcinogenesis. 2013; 34:2231-2239.

41. Li H, Zhao J, Zhang JW, Huang QY, Huang JZ, Chi LS, Tang HJ, Liu GQ, Zhu DJ, Ma WM. MicroRNA-217, down-regulated in clear cell renal cell carcinoma and associated with lower survival, suppresses cell proliferation and migration. Neoplasma. 2013; 60:511-515.

42. Zhao J, Lei T, Xu C, Li H, Ma W, Yang Y, Fan S, Liu Y. MicroRNA-187, down-regulated in clear cell renal cell carcinoma and associated with lower survival, inhibits cell growth and migration though targeting B7-H3. Biochem Biophys Res Commun. 2013; 438:439-444.

43. Chen X, Ruan A, Wang X, Han W, Wang R, Lou N, Ruan H, Qiu B, Yang H, Zhang X. miR-129-3p, as a diagnostic and prognostic biomarker for renal cell carcinoma, attenuates cell migration and invasion via downregulating multiple metastasis-related genes. J Cancer Res Clin Oncol. 2014; 140:1295-1304.

44. Ishihara $\mathrm{T}$, Seki N, Inoguchi S, Yoshino H, Tatarano S, Yamada Y, Itesako T, Goto Y, Nishikawa R, Nakagawa M, Enokida H. Expression of the tumor suppressive miRNA$23 \mathrm{~b} / 27 \mathrm{~b}$ cluster is a good prognostic marker in clear cell renal cell carcinoma. J Urol. 2014; 192:1822-1830.

45. Goto K, Oue N, Shinmei S, Sentani K, Sakamoto N, Naito Y, Hayashi T, Teishima J, Matsubara A, Yasui W. Expression of is a potential prognostic factor after nephrectomy in advanced renal cell carcinoma. Mol Clin Oncol. 2013; 1:235-240.

46. Shinmei S, Sakamoto N, Goto K, Sentani K, Anami K, Hayashi T, Teishima J, Matsubara A, Oue N, Kitadai Y, Yasui W. MicroRNA-155 is a predictive marker for survival in patients with clear cell renal cell carcinoma. Int $\mathrm{J}$ Urol. 2013; 20:468-477.

47. White NM, Yousef GM. MicroRNAs: exploring a new dimension in the pathogenesis of kidney cancer. BMC Med. 2010; 8:65.

48. Catto JW, Alcaraz A, Bjartell AS, De Vere White R, Evans CP, Fussel S, Hamdy FC, Kallioniemi O, Mengual L, Schlomm T, Visakorpi T. MicroRNA in prostate, bladder, and kidney cancer: a systematic review. Eur Urol. 2011; 59:671-681.

49. Nair VS, Maeda LS, Ioannidis JP. Clinical outcome prediction by microRNAs in human cancer: a systematic review. J Natl Cancer Inst. 2012; 104:528-540.

50. Jamali Z, Asl Aminabadi N, Attaran R, Pournagiazar F, Ghertasi Oskouei S, Ahmadpour F. MicroRNAs as 
prognostic molecular signatures in human head and neck squamous cell carcinoma: A systematic review and metaanalysis. Oral Oncol. 2015; 51:321-331.

51. Huang QB, Ma X, Zhang X, Liu SW, Ai Q, Shi TP, Zhang Y, Gao Y, Fan Y, Ni D, Wang BJ, Li HZ, Zheng T. DownRegulated miR-30a in Clear Cell Renal Cell Carcinoma Correlated with Tumor Hematogenous Metastasis by Targeting Angiogenesis-Specific DLL4. PLoS One. 2013; 8:e67294.

52. Ma X, Shen D, Li H, Zhang Y, Lv X, Huang Q, Gao Y, Li X, Gu L, Xiu S, Bao X, Duan J, Zhang X. MicroRNA-185 inhibits cell proliferation and induces cell apoptosis by targeting VEGFA directly in von Hippel-Lindau-inactivated clear cell renal cell carcinoma. Urol Oncol. 2015.

53. Volinia S, Calin GA, Liu CG, Ambs S, Cimmino A, Petrocca F, Visone R, Iorio M, Roldo C, Ferracin M, Prueitt RL, Yanaihara N, Lanza G, Scarpa A, Vecchione A, Negrini M, et al. A microRNA expression signature of human solid tumors defines cancer gene targets. Proc Natl Acad Sci U S A. 2006; 103:2257-2261.

54. Capodanno A, Boldrini L, Proietti A, Ali G, Pelliccioni S, Niccoli C, D'Incecco A, Cappuzzo F, Chella A, Lucchi M, Mussi A, Fontanini G. Let-7g and miR-21 expression in non-small cell lung cancer: correlation with clinicopathological and molecular features. Int J Oncol. 2013; 43:765-774.

55. Schee K, Lorenz S, Worren MM, Gunther CC, Holden M, Hovig E, Fodstad O, Meza-Zepeda LA, Flatmark K. Deep Sequencing the MicroRNA Transcriptome in Colorectal Cancer. PLoS One. 2013; 8:e66165.

56. Seca H, Lima RT, Lopes-Rodrigues V, Guimaraes JE, Almeida GM, Vasconcelos MH. Targeting miR-21 induces autophagy and chemosensitivity of leukemia cells. Curr Drug Targets. 2013; 14:1135-1143.

57. Zhou X, Wang X, Huang Z, Wang J, Zhu W, Shu Y, Liu P. Prognostic Value of miR-21 in Various Cancers: An Updating Meta-Analysis. PLoS One. 2014; 9:e102413.

58. Dey N, Das F, Ghosh-Choudhury N, Mandal CC, Parekh DJ, Block K, Kasinath BS, Abboud HE, Choudhury GG. microRNA-21 governs TORC1 activation in renal cancer cell proliferation and invasion. PLoS One. 2012; 7:e37366.

59. Li X, Xin S, He Z, Che X, Wang J, Xiao X, Chen J, Song X. MicroRNA-21 (miR-21) post-transcriptionally downregulates tumor suppressor PDCD4 and promotes cell transformation, proliferation, and metastasis in renal cell carcinoma. Cell Physiol Biochem. 2014; 33:1631-1642.

60. Youssef YM, White NM, Grigull J, Krizova A, Samy C, Mejia-Guerrero S, Evans A, Yousef GM. Accurate molecular classification of kidney cancer subtypes using microRNA signature. Eur Urol. 2011; 59:721-730.

61. Khella HW, White NM, Faragalla H, Gabril M, Boazak M, Dorian D, Khalil B, Antonios H, Bao TT, Pasic MD, Honey RJ, Stewart R, Pace KT, Bjarnason GA, Jewett MA, Yousef GM.
Exploring the role of miRNAs in renal cell carcinoma progression and metastasis through bioinformatic and experimental analyses. Tumour Biol. 2012; 33:131-140.

62. Slaby O, Redova M, Poprach A, Nekvindova J, Iliev R, Radova L, Lakomy R, Svoboda M, Vyzula R. Identification of MicroRNAs associated with early relapse after nephrectomy in renal cell carcinoma patients. Genes Chromosomes Cancer. 2012; 51:707-716.

63. Juan D, Alexe G, Antes T, Liu H, Madabhushi A, Delisi C, Ganesan S, Bhanot G, Liou LS. Identification of a microRNA panel for clear-cell kidney cancer. Urology. 2010; 75:835-841.

64. Weng L, Wu X, Gao H, Mu B, Li X, Wang JH, Guo C, Jin JM, Chen Z, Covarrubias M, Yuan YC, Weiss LM, Wu H. MicroRNA profiling of clear cell renal cell carcinoma by whole-genome small RNA deep sequencing of paired frozen and formalin-fixed, paraffin-embedded tissue specimens. J Pathol. 2010; 222:41-51.

65. White NM, Bao TT, Grigull J, Youssef YM, Girgis A, Diamandis M, Fatoohi E, Metias M, Honey RJ, Stewart R, Pace KT, Bjarnason GA, Yousef GM. miRNA profiling for clear cell renal cell carcinoma: biomarker discovery and identification of potential controls and consequences of miRNA dysregulation. J Urol. 2011; 186:1077-1083.

66. Fridman E, Dotan Z, Barshack I, David MB, Dov A, Tabak S, Zion O, Benjamin S, Benjamin H, Kuker H, Avivi C, Rosenblatt K, Polak-Charcon S, Ramon J, Rosenfeld N, Spector Y. Accurate molecular classification of renal tumors using microRNA expression. J Mol Diagn. 2010; 12:687-696.

67. Redova M, Poprach A, Besse A, Iliev R, Nekvindova J, Lakomy R, Radova L, Svoboda M, Dolezel J, Vyzula R, Slaby O. MiR-210 expression in tumor tissue and in vitro effects of its silencing in renal cell carcinoma. Tumour Biol. 2013; 34:481-491.

68. Huang X, Zuo J. Emerging roles of miR-210 and other non-coding RNAs in the hypoxic response. Acta Biochim Biophys Sin (Shanghai). 2014; 46:220-232.

69. Yang J, Zhang JY, Chen J, Xu Y, Song NH, Yin CJ. Prognostic role of microRNA-221 in various human malignant neoplasms: a meta-analysis of 20 related studies. PLoS One. 2014; 9:e87606.

70. Sutton AJ, Song F, Gilbody SM, Abrams KR. Modelling publication bias in meta-analysis: a review. Stat Methods Med Res. 2000; 9:421-445.

71. Zwahlen M, Renehan A, Egger M. Meta-analysis in medical research: potentials and limitations. Urol Oncol. 2008; 26:320-329.

72. Wu X, Weng L, Li X, Guo C, Pal SK, Jin JM, Li Y, Nelson RA, Mu B, Onami SH, Wu JJ, Ruel NH, Wilczynski SP, Gao H, Covarrubias M, Figlin RA, et al. Identification of a 4-microRNA signature for clear cell renal cell carcinoma metastasis and prognosis. PLoS One. 2012; 7 :e35661. 
73. Fritz HK, Lindgren D, Ljungberg B, Axelson H, Dahlback B. The $\operatorname{miR}(21 / 10 b)$ ratio as a prognostic marker in clear cell renal cell carcinoma. Eur J Cancer. 2014; 50:1758-1765.

74. Stroup DF, Berlin JA, Morton SC, Olkin I, Williamson GD, Rennie D, Moher D, Becker BJ, Sipe TA, Thacker SB. Metaanalysis of observational studies in epidemiology: a proposal for reporting. Meta-analysis Of Observational Studies in Epidemiology (MOOSE) group. JAMA. 2000; 283:2008-2012.

75. Moher D, Liberati A, Tetzlaff J, Altman DG, Group P. Preferred reporting items for systematic reviews and meta-analyses: the PRISMA statement. BMJ. 2009; 339:b2535.

76. Parmar MK, Torri V, Stewart L. Extracting summary statistics to perform meta-analyses of the published literature for survival endpoints. Stat Med. 1998; 17:2815-2834.

77. Tierney JF, Stewart LA, Ghersi D, Burdett S, Sydes MR. Practical methods for incorporating summary time-to-event data into meta-analysis. Trials. 2007; 8:16. 